\title{
2017年药监改革全年回顾
}

\author{
陈小娟
}

研发客

回顾刚结束的 2017 年, 用一句话总结医药行业的政策动态, 可以说是药监改革势如破竹。从 3 月调整 进口药品注册管理的征求意见稿, 到 5 月四项征求意见稿, 再到 6 月 $\mathrm{CFDA}$ 加入 $\mathrm{ICH}, 10$ 月两办发布《关于 深化审评审批制度改革鼓励药品医疗器械创新的意见》(以下简称《深化改革意见》), 以及《药品管理法》 和《药品注册管理办法》公开征求意见, 这几项改革文件在发布之后都在业内引起了极大反响, 甚至成为各 大会议讨论的主题。在药监部门密集的政策动态下, 行业对于新政的响应和调整, 从业者对于药品开发、临 床试验、新药审评审批等事物的看法正悄然改变, 投资者透过新政敏锐地察觉到制药企业研发策略的调整, 这些都提示着改革政策已开始逐步落地。

始于 2015 年的药审改革, 在过去的两年里从不同的角度着力布局全新的医药产业生态环境。行业对于自 查核查、一致性评价、MAH、优先审评等稍早出台的政策已经逐渐适应, 在落实过程中也取得了不少阶段性成果。 比如严肃数据造假查处上升法律高度、17 个仿制药完成一致性评价、MAH 试点后收到注册申请 560 件、423 个药品注册申请被纳入了优先审评。其中最重要的一个突破是在短时间内解决了药品注册申请积压这一历史遗 留问题, 目前药品注册申请已经由 2015 年高峰时的 22000 件减少至不到 4000 件, 化学药、中药等多类注册 申请已实现按时限批准。优先审评的目的也由最初的解决注册申请积压, 逐渐转向鼓励创新和满足临床需要上。

如果说 2016 年改革的侧重点是解决药品注册申请积压和提高药品标准。那么在过去的 2017 年里, 药审 改革的方向则侧重于尽可能满足临床需要, 以及与国际接轨。行业的关注也从原来的药品质量的提高, 逐渐 转移到鼓励药物创新上, 法规的变动则更多集中在改革药物临床试验管理和临床能力的组建上。

\section{1. 改革临床试验管理}

2017 年 3 月, 总局发布《关于调整进口药品注册管理有关事项的决定》的征求意见稿, 行业越来越多的人开 始真正关注到药物临床试验生态上。新政在放开国际多中心临床试验 (IMCT) 的限制的同时, 还取消了进口新药 申报 NDA 时上市许可证书 CPP 的要求。一方面是新政所构建的全球竞争舞台在鼓励创新药物尽快进入中国、惠 及患者的同时, 很有可能会让临床资源紧缺的问题愈加突出。另一方面也意味着国内研究者、CRO 能够有机会参 与到新药临床开发的早期阶段, 从而提升各方临床开发经验和能力, 为将来更长远的目标 (在中国做新药) 而准备。

2017 年里, 临床试验机构资格认定实行备案管理无疑成为讨论的热点话题。机构备案制从 2016 年首次提及 开始, 一路从争议中走来, 直到目前药物临床试验机构的备案管理仍未迎来政策的正式落地 (医疗器械临床试验 机构的备案管理已于今年 1 月 1 日正式实施)。在此期间, CFDA 并未停止对医疗机构进行药物临床试验资格认 定的工作。根据 CFDA 官网, 2017 年共计有 156 家医疗机构通过资格认定, 106 家机构新增专业获得认定资格, 268 家医疗机构及所列专业通过资格认定复核检查, 目前共计 626 家医疗机构被认定具有药物临床试验机构资格。 这些数据都提示着 CFDA 与往年相比, 正在加快机构资格认定步伐 (2017 年以前最近的一批药物临床试验机构 资格认定清单在 2014 年发布)。另一边, 总局还发布了《药物临床试验机构资格认定服务指南》, 这更让不少人 对备案制的推行产生质疑。

换个角度看, 无论是加紧资格认定工作, 还是推行备案制, 目的都在于增加临床试验机构数量以满足日 益增长的临床试验需求, 这种需求主要来源于一大批正在崛起的本土创新药企。而备案制出现在两办《深化 改革意见》, 《药品注册管理办法》、GCP 等多个法律法规的修订稿中, 也提示着在法规的顶层设计上已经 嵌入了备案制, 临床试验机构管理下一步的方向是备案制, 这母庸置疑。只是在备案制正式实施之前, 仍有 医疗机构有申请资格认定的需要, 企业对临床试验机构的需求远远未满足, 因此这一阶段的资格认定可以看 


\begin{tabular}{|c|c|c|}
\hline 改革临床试验管理 & 相关文件 & 落地状况 \\
\hline $\begin{array}{l}\text { 1. 临床试验机构资格 } \\
\text { 认定实行备案管理 }\end{array}$ & $\begin{array}{l}\text { 《医疗器械临床试验机构条件和备案管理办法》 } \\
\text { 《药物临床试验机构管理规定》 }\end{array}$ & $\begin{array}{l}\text { 己实施 } \\
\text { 征求意见结束 }\end{array}$ \\
\hline $\begin{array}{l}\text { 2. 支持临床试验机构 } \\
\text { 和人咞展临试验 }\end{array}$ & 暂无 & \\
\hline 3. 完善伦理委员会机制 & 暂无 & \\
\hline 4. 提高伦理审查效率 & 暂无 & \\
\hline 5. 优化临床试验审批程序 & 《关于调整药物临床试验审评审批的公告(征求意见稿)》 & 征求意见结束 \\
\hline 6. 接受境外临床试验数据 & 《接受境外临床试验数据的技术要求》 & 征求意见结束 \\
\hline 7. 支持拓展性临床试验 & 《拓展性同情使用临床试验用药物管理办法》 & 征求意见结束 \\
\hline 8. 严肃査处数据造假行为 & $\begin{array}{l}\text { 《最高人民法院、最高人民检察院关于办理药品、医疗器 } \\
\text { 械注册申请料造假刑事案件适用法律若干问题的解释》 } \\
\text { 《关于药物临床试验数据核査有关问题处理意见的公告 } \\
\text { (修改稿)》》 }\end{array}$ & 已实施 \\
\hline
\end{tabular}

表格由研发客整理

作是为顺利衔接过渡新旧政策的求稳策略，也是对创新药企的另一种支持。

除机构备案制外，在 10 月初两办发布的《深化改革意见》还提出了另外 7 项措施从不同角度推进临床试 验管理的改革, 各项措施落实情况详见上表。由表可知, 在改革临床试验管理这一方向上, 过半的措施已有 具体细则出台, 预计这些已经结束征求意见的文件很快会在 2018 年落地。关于完善伦理委员会机制和提高 伦理审查效率方面的内容，尽管尚未有细则或意见稿出来，但同样受到行业关注。伦理前置、中心伦理、区 域伦理等新措施的出现, 也对伦理委员会的审查能力和效率提出了更高的要求, 借鉴其他国家或地区的经验, 众人正在寻求更稳健、更优化的伦理审查模式。

\section{2. 全新药监形象}

改革临床试验管理中，药监部门从 2015 改革伊始就做了不少优化临床试验审批程序的工作，如对推行 优先审评、建立沟通交流机制等。但在过去的 2017 年里，最让人拍手叫好的一项制度叫做 60 天 IND。即审 评机构自受理之日起 60 个工作日后, 没有给出否定或质疑的审查意见即视为同意, 申请人可按照递交的方案 开展临床试验。尽管这项新政尚未真正落地，但消息一出便足以激动一批制药人。如果说以自查核查来缓解 审评积压彰显的是药监部门在提升质量上的果断, 那么 60 天 IND 展现的就是药监部门的勇敢, 敢于突破此 前为自己设立的保护伞。因为后续新政执行将会面临极大的挑战, 审评机构的人手、培训、Pre-IND meeting 能否有效安排，这些都将影响着政策施行效果。

从明示许可到默示许可是审评方式的转变，也是药品监管史上的一大进步。更有人评价：这一新政的良 好执行，对于中国医药工业界特别是创新药的发展将会是划时代的影响。以 60 天 IND 为代表，在 2017 年 的密集政策之下，可以清晰看到不少监管制度和监管方式的创新。改革进程中逐步塑造的全新药监形象也让 人眼前一亮, 智慧、多部委协作、高效, 这些逐渐成为了新时代下药监形象的几个众望所归的关键词。

智慧：谈及此番药审改革，不少业内人士倾向于用 “智慧” 一词来评价。在药品注册申请积压和临床数 据质量两大问题上，药监部门的做法堪称 “四两拨千斤”。药品医疗器械临床试验机构备案， BE 试验备案， 取消 GMP、GSP、GCP、GLP 等认证的行政审批事项，这些改变并不意味着放松了对行业各方的监管。相反， 这是一种监管理念的进步：唯能力不唯机构, 从以行政程序化为主导到以科学论证为导向的审评，由过去的 各环节事前监管改为药品全生命周期的持续合规，以飞行检查和和严厉处罚倒逼各方合法合规、提高质量。

改革政策日新月异的同时，监管方与产业界的沟通也越来越密切，在稍微大型一些的专业会议上，总能 看到监管部门相关人员的身影。在媒体上，也会不时看到监管部门老师的发声。开放交流的窗口，监管与被 
监管双方的紧密互动和充分沟通, 让一个个棘手的问题迎刃而解, 这何尝不是一种大智慧。尤其值得一提的 是, 在这一年里关于人类遗传资源管理问题的优化, 这是产业与监管方长达两年多的谈判成果, 更是双方博 亦中寻找到平衡点的一次成功案例。

多部委协作: 以 CFDA 为主要监管方, 我国药品监管体系框架下还涉及了卫计委、人类遗传资源办公室、 知识产权部门等多个部门。两办《深化改革意见》专门对此提出明确指示：各相关部门要依法履职, 分工协作, 形成改革合力。另一方面, 《药品管理法》、《药品注册管理办法》、《药物临床试验质量管理规范》等多个自 上而下的相关法律法规正处于修订状态, 修订内容融合了新一轮药审改革的各项改革措施。这两个方向的改 变提示着在国家顶层设计上所推动的药审改革, 将解决长期以来药监不能突破部委规章制度、审评不能突破 上位法这类问题，在国家食品药品监管部门的牵头之下，一系列利好新政有望逐一落地。

高效: 在 2017 年里, CDE 共计公布了 13 批拟纳入优先审评的名单, 227 个项目纳入优先审评; 组织了 93 场专家咨询会议, 完成 176 项特殊审评……这一串数据背后, 是一个更加高效的药品审评部门。尤其值得 一提的是, 这一年里由优先审评审批加快上市的药品开始出现, 如阿斯利康的泰瑞沙 (奥希替尼, AZD9291) 从首次提交临床申请到上市不到 3 年、信达生物的 PD-1 单抗 (IBI308) 从临床走到上市申请仅用了一年多、 勃林格殷格翰的尼达尼布从上市申请到获批仅 5 个月完成。随着药品审评团队的扩大和审评能力的提高, 充 分利用沟通交流机制和专家咨询委员会，未来将会有更多高质量新药以更快的速度开发上市并应用到临床。

\section{3. 国际化的最终目标}

CFDA 局长毕井泉在 10 月份的一次新闻发布会上表示：改革最终的目标是与国际接轨。在忙碌的 2017 年里, 我们确实看到了药监部门在这个目标上所做的努力。比如, 加入 ICH 并迎来了 ICH 指导原则首度在国 内征求意见, 这是参与国际规则的制定; 放开国内开展 IMCT 的限制、探索接受境外临床试验数据的审评 方式, 这是在国内构建开放的全球竞争舞台; 全面推进一致性评价是提高国内仿制药水准至国际高度; 探索 设立拓展性试验机制、同情用药机制、药品专利链接制度等, 这是借鉴国际通用做法提高监管科学; 翻译 和参考国际指南, 修订国内政策法规, 在政策体系上与国际标准一致。

以国际化为改革最终目标, 此番改革可以说是在全方位、系统化、大力度地重塑药品监管体系, 并紧紧 围绕着鼓励创新和提高质量这两个方面来修订和完善政策法规。尤其是《中国上市药品目录集》的建立, 这 一借鉴国际通行的做法 (橙皮书), 早在几年甚至更早就被行业呼吁已久。目录集在建立之初就被行业抱以 较高的期望, 比如为药品的开发提供客观的标准, 引导仿制药企业有序开发; 通过罗列相关专利信息, 降低 潜在的专利侵权风险; 提高药品质量、保护创新者权益。而在一年将近尾声之际出炉了首批目录名单, 目前 收录了 131 个品种, 203 个品种规格, 其中包括通过一致性评价的 13 个品种, 17 个品规。未来, 借鉴国际的 做法, 将会引进更多合理、可行、利好行业发展的机制进入到中国, 在国内开发药物将不再是 “望洋兴叹”。

值得一提的是, 大多时候业内人士自信国内的设备、人才、资金、技术等硬件方面已经或者很快能够达 到国际水平。但在意识形态如 GCP 执行、风险把控、受试者保护等这一软件方面与国际水平的差距, 却不 是在短时间内可以完成转变, 这可能需要几个十年来追赶。可以预见的是, 药监部门在接下来的一段时间里 的改革工作可能比以往任何时候都更具挑战性。因为推进这些改革措施的进一步落地, 还需要制定和完善更 多的指导细则, 从旧到新的过渡也不可能一蹴而就。如何把政策变成制度, 把制度以法律法规固定下来? 这 些都决定着改革的成果能否延续, 以及在多大程度上达到预期效果。

无论如何, 在 2017 年里监管部门围绕药审改革所做的布局和努力, 给了我们很多信心, 让行业有理由相信 中国新药研发黄金期即将到来, 让人们相信未来将会有更多的好药更快进入市场, 从而改善患者健康, 甚至救命。

注: 文章数据来源 CFDA、CDE 官网, 以及 12 月 23 日 CFDA 副局长、党组成员孙咸泽出席 2017 年北 京药学年会时, 所做的报告 ---《学习贯彻十九大精神, 深化药品监管制度改革, 鼓励医药经济创新发展》

真诚感谢常建青、顾娟红、李静怡、储旻华、郝鹏、孙海顺等各位老师对本文的指导和支持。 